\title{
Article
}

\section{The impact of advertising creativity, warning-based appeals and green dispositions on the attentional effectiveness of environmental advertisements}

Shen, Wangbing, Gu, Haixia, Ball, Linden, Yuan, Yuan, Yu, Cheng, Shi, Rong and Huang, Taozhen

Available at http://clok.uclan.ac.uk/34028/

Shen, Wangbing, Gu, Haixia, Ball, Linden ORCID: 0000-0002-5099-0124, Yuan, Yuan, Yu, Cheng, Shi, Rong and Huang, Taozhen (2020) The impact of advertising creativity, warning-based appeals and green dispositions on the attentional effectiveness of environmental advertisements. Journal of Cleaner Production, 271 . p. 122618. ISSN 0959-6526

It is advisable to refer to the publisher's version if you intend to cite from the work. http://dx.doi.org/10.1016/j.jclepro.2020.122618

For more information about UCLan's research in this area go to http://www.uclan.ac.uk/researchgroups/ and search for <name of research Group>.

For information about Research generally at UCLan please go to http://www.uclan.ac.uk/research/

All outputs in CLoK are protected by Intellectual Property Rights law, including Copyright law. Copyright, IPR and Moral Rights for the works on this site are retained by the individual authors and/or other copyright owners. Terms and conditions for use of this material are defined in the policies page. 
This is the final version of a manuscript that has been accepted for publication in Journal of Cleaner Production. The published version of record may differ slightly from this manuscript.

\title{
The Impact of Advertising Creativity, Warning-Based Appeals and Green Dispositions on the Attentional Effectiveness of Environmental Advertisements
}

\author{
Wangbing Shen ${ }^{1}$, Haixia Gu${ }^{1}$, Linden J Ball ${ }^{2}$, Yuan Yuan ${ }^{3}$, Cheng $\mathrm{Yu}^{4}$, \\ Rong Shi ${ }^{5}$, Taozhen Huang ${ }^{1}$ \\ 1 School of Public Administration and Business School, Hohai University, Nanjing, China \\ 2 School of Psychology, University of Central Lancashire, Preston, UK \\ 3 School of Education and Jiangsu Provincial key Laboratory of Special Children's Impairment \\ and Intervention, Nanjing Normal University of Special Education, Nanjing \\ 4 East Campus, China Construction Bank University, Changzhou, China \\ 5 School of Psychology, Nanjing Normal University, Nanjing, China
}

Correspondence should be sent to:

Dr. Prof. Wangbing Shen, Hohai University, Email: wangbingshpsy@163.com

Dr. Prof. Linden J Ball, University of Central Lancashire, Email: lball@uclan.ac.uk

Dr. Yuan Yuan, Nanjing Normal University of Special Education, Email: psychyy1989@163.com

Dr. Prof. Taozhen Huang, Hohai University, Email: 1516420098@qq.com

Acknowledgement: This work was supported by the Fundamental Research Funds for the Central Universities (B200202152; B200204015; 2017B14514), the Natural Science Foundation of Jiangsu Province (BK20181029), the Key Program of National Natural Science Foundation of China (91747208), the National Natural Science Foundation of China (31500870), China Postdoctoral Science Foundation (2017M621603); Natural Science Foundation of Jiangsu College of China (17KJB190002), and the Philosophical and Social Science Foundation of Jiangsu Colleges of China (2017SJB0649).

\section{Compliance with ethical standards}

This study has been approved by institutional ethical committees and is in compliance with ethical standards.

\section{Conflict of Interest}

There is no conflict of interest to declare. 


\section{Highlights}

- Selective attention to environmental advertisements was examined

- An attentional blink effect was found in the context of environmental advertising

- Selective attention was greater to creative versus standard environmental advertising

- Selective attention to environmental advertising was related to altruistic value 


\title{
The Impact of Advertising Creativity, Warning-Based Appeals and Green Dispositions on the Attentional Effectiveness of Environmental Advertisements
}

\begin{abstract}
Accompanying the growing call for ecological sustainability, environmental advertising is playing an increasingly important role in green marketing to foster environmental concern and pro-environmental behavior. The present study examined the impact of two factors on people's selective attention to green advertisements: advertising creativity (by comparing creative vs. standard advertisements) and appeal type (by comparing warning-based vs. vision-based appeals). The study also investigated the association between advertising effectiveness and individual differences in levels of green dispositions, including environmental concern and value orientation. To explore these issues the study employed a Rapid Serial Visual Presentation paradigm to measure the magnitude of the "attentional blink" arising from people attending to environmental advertisements of varying creativity and appeal type. Findings revealed a significant attentional blink effect for environmental advertising (indicative of heightened selective attention) that was greater for creative advertisements than standard advertisements. A significant association was also found between the magnitude of the attentional blink and dispositional differences in environment-related altruistic value. Results extend previous findings relating to the attentional blink as an index of advertising effectiveness, and shed light on the importance for green marketing of advertising creativity, advertising appeal and environmental value.
\end{abstract}

Keywords: attentional blink; creative advertising; advertising appeal; pro-environmental behavior

\section{Introduction}

A green earth free from pollution and waste is the dream home to foster us and future generations. However, rapid economic development, non-sustainable consumption, industrialization and an increasing global population, can no longer be dissociated from their adverse environmental impacts. Such impacts often manifest as major environmental disasters and extreme events that are underpinned by multiple interacting factors such as: drastic changes in climate; significant ozone-layer depletion; increased water and air pollution and acid rain; heightened soil degradation, desertification and deforestation; and continuing damage to flora and fauna. These alarming issues have seriously affected the natural environment, leading to calls for more radical sustainable and environment-friendly practices (World Health Organization, 2008).

Environmental conservation efforts also involve the general public. To develop a sustainable society, it is necessary to lead citizens' attitudes and behaviors in environment-friendly directions, rather than focusing solely on changes to company practices. Accordingly, actions developed to protect the environment should be embraced by various stakeholders and should extend to countermeasures such as reducing waste and lowering greenhouse gas emissions that can only be attained through extensive public participation (Brunson and Reiter, 1996; McKenzie-Mohr, 2000). The media can also play an important role in mobilizing such participation through delivering environment-related information to strengthen people's environmental concerns (Rios et al., 2006) and shape long-term environmental attitudes (Do Paço and Raposo, 2008).

Environmental advertising is conveyed to the general public through various media, including television, radio, magazines, newspapers and the Internet. Such advertising is believed to have considerable potential to foster sustainable behaviors (e.g., VanDyke and Tedesco, 2016) 
and is particularly useful in informing and persuading citizens to become acquainted with activities related to environmental protection (Leonidou et al., 2011; Ketelsen et al., 2020) such as replacing harmful chemicals with recycled products, acting in ways that conserve the environment, increasing priorities related to environmental issues when making decisions, improving awareness of environmental risks and issues, and engaging in a green lifestyle such as reducing plastic waste, consuming green products and donating money to tackle environmental problems (Casado-Aranda et al., 2018). Indeed, Huang (2016) reported that being exposed to news coverage related to global warming greatly facilitates individuals' pro-environmental intentions (e.g., environmental civic engagement) and proactive environmental behavior (e.g., daily, pro-environmental practices). However, the effectiveness of such advertisements has not yet been sufficiently examined.

Most studies examine the effectiveness of environmental advertisements from the perspective of the supply chain (Jäger and Weber, 2020; Kurisu et al., 2019; Li et al., 2020; Šomplák et al., 2019), assessing the role of environmental advertising campaigns in improving an organization's image, in implementing corporate environmental responsibility and in promoting eco-friendly products and offerings. In contrast, very limited investigation has focused on the effectiveness of environmental advertising from the perspective of constructing an ecological civilization or environmental sustainability per se. This is despite the fact that a majority of environmental advertisements are issued and campaigned by non-commercial organizations, including central and local governments and non-profit organizations such as the World Wildlife Fund, especially in certain developing countries (e.g., China), that are actively and officially striving to achieve their carbon-emission targets as agreed at the UN Climate Change Conference in Paris in 2015.

Of vital importance to the success of environmental advertising is its capacity to attract and sustain people's attention. Environmental advertisements need to be more effective at attracting attention than other advertisements if they are to facilitate eco-friendly influences and reduce eco-harmful impacts. Only in this way can environmental advertisements that are campaigned to protect the environment or ensure efficient use of energy and resources be considered to achieve goals that are consistent with their claims by virtue of being positive exemplars of environmentally-friendly products that are highly energy-efficient whilst persuading the audience to protect the environment. Otherwise, environmental advertisements that are inefficient or ineffective and that cannot even attract attention will, paradoxically, be deemed to be a waste of resource and a negative exemplar of the very environmental protection that they advocate.

Environmental advertising has grown dramatically during the past two decades (Low and Mohr, 2000; Yoo et al., 2004), as exemplified by a proliferation of advertisements from many homogeneous and ferociously competitive eco-friendly brands and products, such that attracting an individual's attention and persuading them seems to be a critical issue for advertising practitioners. As Hsieh and Chen (2011) have argued, advertising should be discussed in the domain of "selective attention". Although the effectiveness of advertising in terms of selective attention has garnered enormous interest in commercial marketing (Zhang and Yuan, 2018), no published research appears to have directly examined such effectiveness in relation to environmental advertising, with existing research only reporting findings derived from retrospective self-reports of attention to environmental advertisements (e.g., Verbeke and Ward 2006). Indeed, in a systematic review of 114 studies on green advertising, Matthes (2019) points out that research has completely ignored the involvement of attention in environmental advertising, hindering an understanding of its role in the success of such advertisements. According to the 
Advertising Research Foundation, attention to advertising is the first stage at which consumers react to the message embedded within an advertisement (Wilson and Casper, 2016).

Despite attention being hard to measure directly and objectively in relation to advertising (e.g., Heath et al., 2006), there is no doubt that attentional capture has significant implications to ensure that advertising is effective (Pieters and Wedel, 2004). Not only is it essential that environmental advertisements attract the public's initial attention, but it is also critical for attention to drive a "mere exposure" mechanism that cultivates familiarity with, and preference for, a brand or product. Furthermore, examining how to facilitate an individual's selective attention to environmental advertising is an important issue given reports that many environmental advertisements have failed to achieve their desired effectiveness in encouraging green sentiments and pro-environmental behaviors (Kronrod et al., 2012). We propose here that issues regarding the effectiveness of environmental advertising might be investigated profitably in terms of the "attentional blink" phenomenon, which is a type of inattention that has not yet been examined in the literature on marketing or advertising effectiveness towards environmental advertising.

Regarding the design of environmental advertisements, theories of advertising creativity argue that creativity is the "soul" of an advertisement and plays an important role in advertising effectiveness by virtue of the creative presentation of information and the generation of creative appeal (e.g., Jovanović et al., 2017). According to theories of advertising creativity, environmental advertisements can be divided into two categories by their overall creativity level: one category is "creative advertising" that is rated as creative by the general public or that has won professional awards competitively; the other category is "common" or "standard" advertising that is rated as less creative or that has not won professional awards (see Shen et al., in press-b).

In addition to the influence of overall creativity, environmental advertisements also use various forms of "appeal" to improve their effectiveness in promoting environmental concerns and pro-environmental behaviors. Appeals that involve rational, green or emotional connotations such as fear or guilt have been examined extensively (e.g., Kao and Du, 2020; Li et al., 2020; Šomplák et al., 2019). Different to these frequently examined forms of appeal are two other types of appeal that are common in environmental campaigns: (i) warning-based appeals that are environmentally alarming; and (ii) vision-based appeals concerning environmental prosperity (Shen et al., in press-a). These two appeal types not only integrate loss versus gain frames and negative versus positive emotional valences but also involve distinct time frames that only appear to have been examined by Casado-Aranda et al. (2018). Specifically, warning-based appeals are past-orientated, depicting a negative outcome that can trigger subjective and experiential thoughts that maximize a potential self-threat linked with past eco-harmful behaviors. In contrast, vision-based appeals are future-orientated, presenting positive information or beautiful images occurring in the future that are a consequence of today's pro-environmental behavior.

Environmental advertisements based on these latter two appeals are very different in their visual expression and performance characteristics. As a recent study by Shen et al. (in press-a) shows, although environmental advertisements involving warning-based and vision-based appeals were judged to be of equal beauty (mainly drawn from their good intention to persuade environmental protection), they are very different in artistic expression and performance. Generally, warning-based environmental advertisements aim to warn people to focus on environmental issues and persuade them to protect the environment by presenting negative or threatening environmental information or mostly gray, black, monotonous and dull scenery. In 
contrast, vision-based environmental advertisements persuade individuals to protect the environment by presenting an overwhelmingly blue/green, ecological landscape or beautiful, natural environment (Shen et al., in press-a). However, no data regarding the advertising effectiveness of these different appeal types is available. We propose that future-oriented, vision-based advertisements, which also take a positive or gain frame, may not be as persuasive as past-oriented, loss-framed, warning-based advertisements. Therefore, the present study reports a behavioral experiment to determine the advertising effectiveness of creative advertisements using these two distinct appeal types to determine which is better for attracting attention.

\subsection{Aims of the study}

Building on the two prominent research streams that we have outlined, which concern the attentional effectiveness of environmental advertising and the role of advertising creativity in attracting attention, we aim in the present research to explore which environmental advertising messages are best suited to attracting people's attention. Furthermore, several studies have alluded to the phenomenon of inattention in advertising (Bakar et al., 2015; Calder and Sternthal, 1980; Daugherty and Hoffman, 2014; Rosbergen et al., 1997), which appears to be linked to the notion of an attentional blink, which we are also interested in examining. In addition, an emerging interest in the literature on environmental advertising relates to the potential association between individual differences in environment-related or green traits or dispositions and advertising effectiveness (Hartmann et al., 2016). Currently, no systemic evidence on such issues is available as no study has explored them within the domain of environmental advertising.

In light of the aforementioned gaps in our understanding of the efficacy of environmental advertising, the present research used an attentional blink task to address the following primary objectives: (i) to ascertain whether there is an attentional blink in environmental advertising; (ii) to explore the attentional effectiveness of environmental advertising across two different levels of advertising creativity (creative vs. standard advertising) and across two different appeal types (warning-based vs. vision-based appeals); and (iii) to examine the potential association between an individual's environmental concern and the attentional effectiveness of environmental advertising as measured using the magnitude of the attentional blink.

In broader terms, the overarching goal of the present study was to contribute to existing research about how green advertising campaigns could be designed and evaluated to ensure their effectiveness (Leonidou et al., 2011). The reported research adopted an experimental approach to examine creative advertising (e.g., Baack et al., 2008), with a focus on people's behavioral responses to environmental advertisements and the association between their responses and their own dispositions toward having environmental or green concerns.

\subsection{Contribution statement}

We anticipated that the results from the study would help marketers design effective messaging relating to environmental issues. More specifically, we contend that the reported research makes several critical contributions to future research and practice, which we summarise as follows. First, contrasting warning-based advertising that highlights eco-harmful outcomes with vision-based advertising that emphasises positive outcomes can determine which appeal is better at attracting people's attention, providing useful implications for green marketing and more general advertising campaigns. Second, some researchers have criticized previous advertising studies on the grounds that the attentional effectiveness of advertising is very limited and depends heavily on memory measures of attention or on aggregate attentional measures, such as the total 
time spent on an advertisement (see Pieters et al., 2002). By introducing an attentional blink task, which we describe in detail below, the present study successfully addresses such criticisms by not only opening up an avenue to examine directly the attentional effectiveness of advertising without any expensive devices (e.g., eye-tracking systems), but also offering more direct and ecologically-valid data to illustrate the importance of selective attention in advertising effectiveness. More importantly, this is the first study to assess the attentional blink effect in relation to the effectiveness of environmental advertising, thereby providing important insights for advertising within the "attentional economy". Third, the present research consolidates the importance of advertising creativity in advertising effectiveness, enriching an understanding of the role of advertising creativity in arousing attention to environmental advertising and facilitating pro-environmental behaviors. Finally, this research sets out to establish a reliable association between the magnitude of the attentional blink and individual differences in people's environment-related dispositions, showing how people's environmental concerns and values influence their attentional engagement with environmental advertising with various levels of creativity. Taken together, the present study makes an original contribution the literature in terms of the questions that it is addressing and the answers that it is aiming to provide to support future research, marketing practices and environmental campaigns.

\section{Review of Prior Research}

To provide a sound background for our reported research, we review in more detail below the literature that spans five key themes of interest: (i) research examining environmental advertising; (ii) research investigating the attentional effectiveness of environmental advertising, including the role of the attentional blink in selective attention; (iii) research assessing the influence of advertising creativity on advertising effectiveness, particularly studies contrasting the attentional effectiveness of creative versus standard environmental advertisements; (iv) research investigating the influence of appeals in environmental advertising; and (v) research linking green dispositions or traits (Hartmann et al., 2016), especially environmental concerns and environmental values, with the attentional effectiveness of environmental advertising.

\subsection{Environmental advertising}

Many companies and corporates are striving to develop eco-friendly products and integrate environmental issues into their business strategies and activities, including R\&D, manufacturing, design and marketing (Dangelico and Vocalelli, 2017; Foster and Green, 2000). They are also working to develop an ecologically responsible organizational image (Jenkins and Yakovleva, 2006; Walker and Wan, 2012) and fulfil corporate social responsibilities (Easterling et al., 1996; De Vries et al., 2015). These developments are a direct response to the rapid ascendance of the current environmental crisis, accompanied by concerns for ecological sustainability (e.g., acid rain, global warming, air pollution, haze and glacial melt), which mean that companies are having to satisfy the needs of potential consumers who are concerned about environmental issues and who prefer environment-friendly products (Kanchanapibul et al., 2014; Tseng and Hung, 2013).

Environmental advertising or green advertising is a special type of advertising wherein the appeal of "greenness" or sustainability is embedded in an authentic way (Chekima et al., 2016). Such advertising has been broadly advocated and has attracted widespread attention among academics and practitioners. Commonly, environmental advertisements refer to appeals that include ecological and environmental sustainability or nature-friendly messages targeting the needs and desires of environmentally concerned stakeholders (Leonidou et al., 2011; Zinkhan and 
Carlson, 1995). Although environmental advertising has been the focus of a growing number of studies, most of them have only been conducted in the West or in developed countries (see Chan, 2000; Dangelico and Vocalelli, 2017). While the relevant Western literature is relatively abundant, research on the responses of an Eastern audience towards environmental advertising is scare.

Many studies have examined the influence of various factors on the effectiveness of environmental advertising, including executional style (Parguel et al., 2015), environmental claim type (Chan, 2000), advertising appeal (Chang, 2012; Dickinson and Holmes, 2008; Hartmann et al., 2014), cross-cultural issues (Chang, 2006), levels of temporal construal (Chen and Chiu, 2016) and consumer motivation for acquiring green products (Griskevicius et al., 2010). Leonidou et al. (2011) adopted content analysis to identify 473 international green advertisements issued between 1988-2007, which were analysed from the multidimensional perspective of advertising profile, targeting feature, message aspect, copy characteristics and situation point. This analysis showed a gradual shift of emphasis in green advertising from business to consumer buyers, with an emphasis on environment-related consumption. The research also revealed that green advertising is a reactive response by companies that is aimed at alleviating their environmental impact, especially for large multinational corporations in industries accused of polluting the environment.

In an in-depth analysis of 114 studies, Dangelico and Vocalelli (2017) summarized the evolution of the concept of "green marketing" over time, showing how this has moved away from being a tool of traditional marketing to becoming a strategy affecting whole companies. In this way, company-based environmental marketing has shifted from having a focus on specific environmental problems to addressing more global sustainability issues and from dealing with specific products and industries to pervading the whole market. Recently, Matthes (2019) reviewed the existing literature relating to environmental advertising and claimed that efforts should be made to investigate the effectiveness of selective attention that is directed at such advertising and the potential facilitators of attentional effectiveness. In this respect research using eye-tracking as a direct measure of attention to environmental advertising has revealed that imagery relating to nature attracts greater attention than other imagery (Hartmann et al., 2013).

The present study focuses on the attentional effectiveness of environmental advertising across distinct appeals and levels of advertising creativity, with warning-based creative and standard advertising being contrasted with vison-based creative and standard advertising. The study also involved a direct behavioral index of attentional effectiveness in terms of measuring the magnitude of the attentional blink using a Rapid Serial Visual Presentation (RVSP) paradigm. This method also enabled an assessment to be made of the relationship between the magnitude of visual attention or inattention to environmental advertising and people's dispositions relating to the environment as measured using an environmental concern scale.

\subsection{Attentional effectiveness and attentional blink}

The concept of attention suggests that individuals sacrifice the processing of certain information in order to process other information effectively. As such, attention is a selective process whereby limited mental capabilities are assigned to certain aspects of the environment while ignoring others (Wang et al., 2018). One of the most important goals of advertising is to attract and increase attention to an advertisement as a prerequisite for it to be effective. Virtually all "hierarchy-of-effect" models of advertising (e.g., AIDA, DAGMAR) stress the role of attention as the first stage of the advertising process (Pilelienè and Grigaliūnaite, 2016; Yoo et al., 2004). Indeed, eye-tracking research shows that increased attention on advertisements is significantly 
related to sales (Goodrich, 2011). After reviewing the literature on environmental advertising, it is surprising that existing research has almost completely ignored the role of attention in environmental advertising (cf. Matthes, 2019). Perhaps this is because attention is more difficult to measure than other advertising effects such as recall.

Importantly, attention can influence other effectiveness measures of adverting, including recognition and recall (Goodrich, 2011; Rademaker et al., 2015). However, only a few studies have examined the attentional effectiveness of environmental advertising using indirect measures of attention based on memory and attitude or by exploring the effect of induced attention. Furthermore, these approaches suffer from drawbacks. For example, indirect measures of attention based on memory for advertisements or attitudes toward advertisements are poor indicators of what audiences really attend to as attention is not necessarily active and conscious (e.g., Ares et al., 2013; Goodrich, 2011). In addition, inducing increased attention to advertisements cannot reveal the effectiveness of attention directed at such advertisements as this approach is manipulating attention as an independent variable rather than measuring it as a dependent variable.

Attention is traditionally considered to be a limited mental capacity that can be allocated to only a few different tasks at a time based on their category and priority (Greenberg, 2012). It acts as the gatekeeper that selects a subset of stimuli to focus on from the continually changing world, with only the selected stimuli being processed further and delivered into awareness (MacLean et al., 2010). Attentional selection can give rise to attentional fluctuation and inattention, which have been reported to arise when viewing advertisements (Wedel et al., 2008). To demystify such inattention that can accompany attentional selection, the "attentional blink" concept has been developed, which captures the negative impact of previously attended targets on subsequent targets that appear within 200-500 ms. Using a Rapid Serial Visual Presentation (RSVP) task, wherein a stream of stimuli including two targets and various distractors are rapidly displayed, Raymond et al. (1992) were the first to find that individuals often fail to report a second target (T2) that is presented shortly after a first target (T1) that has been immediately and correctly identified, especially when the temporal delay between the two targets is within 200-500 ms (see also Kan et al., 2019). Although many recent studies have examined the cognitive mechanisms underpinning the attentional blink (e.g., Kan et al., 2019; Tang et al., 2020; Trutti et al., 2019), no research appears to have examined this effect in the fields of advertising or environmental psychology.

There are many reasons for companies to embed environment-related information fragments (e.g., advertising slogans) or real-world, environmental scenarios in commercial advertisements. These reasons include the desire to build an environmentally friendly brand-image or to satisfy consumers' needs relating to environmental concerns. In addition, to maximize their brand or organizational influence, an increasing number of corporations and organizations incorporate their brands or services (e.g., brand logos, names or other important organizational elements) into environmental advertisements or schedule the exposure of their commercial advertising spatially or temporally adjacent to environmental advertising. However, audiences do not always view such advertisements in a simultaneous or highly integrated way. Rather, they see them in sequence, with advertising elements being processed sequentially and expanding over time (Sajjacholapunt and Ball, 2014; Zhang and Yuan, 2018). Measuring the attentional blink in such advertising situations can provide a very useful, direct index of the attentional effectiveness of advertisements.

The magnitude of the attentional blink, which is calculated as the difference in the average T2 accuracy at different lags, can be used as a proxy for the attentional effectiveness of 
environmental advertising, Moreover, there is evidence that the magnitude of the attentional blink is correlated with variables related to individual differences in cognition (Dale and Arnell, 2015). For example, Colzato et al. (2007) observed a marked negative correlation between people's working memory span and the maximal attentional blink, which was replicated by Arnell et al. (2010) using an "operation span" measure of individual differences in working memory. We contend that examining the attentional blink effect in relation to environmental advertising is valuable for extending our understanding of the importance of attention in advertising effectiveness concerning eco-friendly behaviors.

\subsection{Advertising creativity}

Creativity is an important issue for advertising practitioners and academics and is viewed as the central component of advertising success (Belch and Belch, 2013). Not only do creative advertisements frequently "pop out" and attract attention (Smith and Yang, 2004; Yang and Smith, 2009), but they are also associated with enhanced attention and interest (Pieters et al., 2002; Till and Baack, 2005). In this respect, Phillips and McQuarrie (2004) argue that when suffering from information overload people will tend to ignore advertisements, such that advertising creativity is critical for ensuring attentional capture (Pilelienè and Grigaliūnaitè, 2016).

Traditionally, advertising textbooks have stressed the "attentional effects" of creative advertisements, namely that they stand out in advertising clutter and therefore receive more attentional resources from potential consumers. However, recent studies are more inclined to examine creative advertisements from the perspective of "contrast effects" (Smith and Yang 2004; Yang and Smith, 2009), in which the heightened attentional effects of creative advertisements are viewed in relative terms as being in opposition to the weaker attentional effects of non-creative, standard advertisements (Pieters et al. 2002, Smith et al. 2007; Shen et al., in press-b). The "contrast effect" produced by creative advertisements makes them stand out in the noise and therefore causes them to attract more attention (Smith and Yang, 2004). To date, no consensus has been achieved to define which advertisements are creative, but a review of extant research reveals that two approaches are dominant. One approach is based on the evaluation of professionals, for example, whether an advertisement has received recognition in prestigious competitions such as the Clio awards. The other approach is based on the general public's ratings of an advertisement's creativity. Evidence has indicated that when advertisements are categorised in terms of having won national, professional awards, they outperform less creative advertisements (without winning such awards) with respect to recall (both immediate and delayed), purchase intention and attitude toward the advertised brand (e.g., Lehnert et al., 2013; Till and Baack, 2005).

Traditionally, a typical means for advertising to attract attention is by creating a distinctive or unusual advertising execution (e.g., Yoo et al., 2004), with the effects on attention of design characteristics such as visual complexity (Pilelienè and Grigaliūnaitè, 2016) being well established (e.g., Janiszewski, 1998; Pieters and Wedel, 2004). Creative advertisements have many unique characteristics compared to standard advertisements, such as novel expressions or concepts and distinctive styles or visual appearances. These characteristics interest the viewer and thus grab attention long enough for the viewer to appreciate them. That is, attention can be "captured" by the features of a stimulus in a bottom-up manner, which contrasts with top-down attention that is "directed" by an individual toward a stimulus to achieve some goal. It has been shown, for example, that advertisements that appear on non-search websites are more likely to capture attention when their features are sufficiently creative or distinctive (Simola et al., 2011). Wilson 
and Casper (2016) also demonstrated that advertising creativity has a positive effect on the recognition of billboard advertising when billboards are large or visually salient. Moreover, creative advertising often impresses the audience because of the novelty of the presented concept or the advertisement's design, but unusual characteristics and ingenious ideas can also make creative advertisements difficult to understand.

Creative advertisements deviate from other advertisements and challenge the audience to understand what the advertising is about, requiring sustained focal attention to the advertised brand and the message being conveyed (Pieters et al., 2002; Yang and Smith, 2009). Indeed, previous studies have revealed that creative advertisements facilitate viewers' initial attention to them compared to standard advertisements and increase the duration of subsequent attention directed at them (Dahlén et al., 2008; Smith et al., 2008; Wilson et al., 2015). As a key driver of competitive advantage, creativity is certain to remain a critical factor in marketing communications in the future (Belch and Belch, 2013; Fillis, 2002). However, there are surprisingly few studies investigating this topic (Stone et al., 2000; Yang and Smith, 2009) and, to date, no research has explored the influence of advertising creativity on green advertising effectiveness within the field of environmental communication or green marketing.

\subsection{Advertising appeal}

The persuasive effects arising from a combination of an advertisement's message and its creative tactics are termed "message appeal", and advertisers use this to influence the way consumers perceive products and to convince them that they are useful (Zhang et al., 2014). Appeal, as the fundamental element of a creative advertising strategy, has been studied extensively. It can be used as a basis to attract the attention of potential consumers to an advertised message, thereby influencing their awareness, beliefs and attitudes towards the advertised product and consequentially their purchase intention (Jovanović et al., 2017). While defining appeal in relation to advertising, Belch and Belch (2004) maintain that it refers to the approach used to draw the audience's attention, motivate and create an interest (Moriarty, 1991) and influence feelings for the advertised object (Jovanović et al., 2017). The influence of appeal on advertising effectiveness has been established. For creative advertising, the attention of viewers directed at such advertising can be improved by highlighting certain advertising appeals (e.g., Awagu and Basil, 2016; Hornik et al., 2017). Grigaliunaite and Pileliene (2016) systemically summarized "rational" and "emotional" appeals in advertising effectiveness, especially in attracting audiences' attention to non-environmental advertising (Albers-Miller and Stafford, 1999).

Selecting the right message appeal is a critical first step in any advertising campaign, including one based on a creative advertising strategy (Sharma and Sing, 2006). However, little is known about the role of message appeal in environmental advertising, where the focus is on changing individual behavior to support an environmental campaign. When matching an appeal with environmental issues whilst also aligning the appeal with a target audience, a primary consideration is the sensitivity surrounding the campaign topic and the difficulty of changing people's habitual behaviors (Rossiter and Bellman, 2005). Naturally, the appeal must be original enough to draw attention, persuasive enough for the target audience to change behavior and subtle enough not to offend (Marchand and Filiatrault, 2002; Noble et al., 2014).

After reviewing previous studies, including ones addressing rational or emotional appeals that are widely used in non-environmental advertising (see Grigaliunaite and Pileliene, 2016; Jovanović et al., 2017; Zhang et al., 2014), it is evident that many other appeals have been 
developed for environmental advertising. These include green appeals (Chen and Chiu, 2016), guilt appeals (Hartmann et al., 2014; Noble et al., 2014), environmental threat appeals (Hartmann et al., 2014), fear appeals (Chen, 2016), functional, fact-based appeals, image-based emotional appeals, as well as a mixed-type appeals combining functional and emotional appeals (Noble et al., 2014; Schmuck et al., 2018). Within this domain, negative emotional appeals that relate to fear, guilt and threat are used most often, although no systematic evidence suggests that their effectiveness is superior to other appeals in changing behavior (Noble et al., 2014).

Two green appeals that are commonly used in practice are warning-based appeals and vision-based appeals, which have both been employed in previous studies (Shen et al., in press-a; Torres et al., 2007). Environmental advertisements that incorporate a warning-based appeal aim to facilitate viewers' pro-environmental behavior or environmental concerns by presenting eco-harmful or negative environment-related information and inducing more negative emotions such as anxiety and fear. In contrast, environmental advertisements that incorporate a vision-based appeal present beautiful, future-oriented, environment-related scenarios or positive information, stimulating more positive experiences of beauty or pleasure. Warning-based appeals tend to be very common in magazine advertisements for a variety of products, including cigarettes, over-the-counter drugs and herbal remedies (e.g., Torres et al., 2007). Willemsen (2005) explored the self-perceived impact of these warnings on the attractiveness of cigarettes and smokers' motivation to quit smoking and found that out of 3973 smokers, $42.2 \%$ showed less attention to cigarettes or less willingness to smoke. Torres et al. (2007) adopted a content analysis of consumer magazines to determine the potential impact of warning-based appeals on the effectives of printed advertisement. They showed more positive responses for recall and attitudes toward the advertisement and brand when the warnings were overtly rather than discreetly placed in printed advertisements. Similarly, Kees et al. (2010) found that more graphic, pictorial, warning depictions strengthened smokers' intentions to stop smoking, with such warnings evoking fear, which in turn mediated the effects of the warning depiction on smokers' intentions to quit. Across three studies, Davis and Burton (2016) revealed that moderately and highly graphic warnings have favorable effects on smoking cessation outcomes and a positive effect on attention to advertising but a negative, indirect effect on purchase intentions relative to text-only warnings or pictorial warnings that are minimally graphic.

To date, no study appears to have examined the impact of warning-based appeals on selective attention directed to environmental advertising or other measures of advertising effectiveness. Similarly, no study seems to have probed vision-based appeals in relation to environmental advertising. Vision-based appeals resemble aesthetic appeals, which tend to elicit more positive evaluations and greater attention for advertising when at a moderate level rather than at low or high levels (Champlin et al., 2014; Vogel and Villegas, 2011).

\subsection{Green traits and dispositions}

Green traits refer to people's dispositional or personality differences associated with environmental sustainability and protection, typically also relating to environmental concern and environmental value, both of which are related to each other (Hartmann et al., 2016; Stern and Dietz, 1994). Indeed, environmental concern builds on environmental value, associating significantly with egoistic, social-altruistic, and biospheric value orientations (Stern \& Dietz, 1994). In essence, environmental concern is tied to anthropocentric altruism: people care about environmental quality mainly because they believe that a degraded environment poses a threat to 
people's health (Fransson and Grling, 1999). Accordingly, individuals with high levels of environmental value and/or environmental concern could be considered pro-environmental.

Environmental concern, as an awareness of environmental degradation and other ecological problems as well as the perception of the necessity to protect the environment (Schmuck et al., 2018; Shukor et al., 2015), is a critical driver for pro-environmental behaviors such as recycling (Hartmann and Apaolaza-Ibanez, 2010; Kim and Choi, 2005). It is also a personal characteristic denoting individuals' general orientation and concern levels toward the environment (Chen and Chiu, 2016). Those who are highly concerned about environmental issues exhibit pro-environmental behavior and green purchasing practices (Chen and Chiu, 2016; Mobley et al., 2013; Schlegelmilch et al., 1996) whilst also ensuring that their lifestyle is less harmful to the environment (Coad et al., 2009). Essentially, environmentally conscious individuals think more abstractly about global concerns, such as long-term goals rather than short-term interests (Agrawal and Wan, 2009; Chen and Chiu, 2016). Existing studies have shown that environmentally conscious individuals engage in a wide range of environmental activities while holding certain values and attitudes, and they purchase products and services that they perceive to have a positive (or less negative) impact on the environment (Roberts, 1996).

Of relevance to the present study is the increasing interest in understanding the association between environmental concern and the effectiveness of environmental advertising. For example, building on a survey from 237 students in Hong Kong, Chan and Han (2014) found that consumers' environmental concern had an impact on attitudes toward advertisements as well as advertising effectiveness, but only for an environmental practice that had high impact and not for one with low impact. Furthermore, Sollberger et al. (2017) used eye-tracking to examine the impact of stable, pre-existing, inter-individual differences in environmental concern on people's selective attention to climate-change images, observing that individuals with high environmental concern spent more time attending to such images compared to individuals with low environmental concern. Given the association between environmental concern and environmental values, together with landscape preferences for environmental value-orientated individuals (Kaltenborn \& Bjerke, 2002), it seems reasonable to assume that environmental values may have the same relationship with the effectiveness of green advertising as does environmental concern.

Many recent studies have also demonstrated a link between the magnitude of people's attentional blink and differences in individual dispositions (e.g., Dale and Arnell, 2015; Lou et al., 2015; van Vugt and Slagter, 2014; Willems and Martens, 2016). However, the association between individual differences in green dispositions such as environmental concern and the magnitude of the attentional blink remains unknown. Accordingly, exploring this association seems fruitful, especially in relation to green traits such as environmental concern and environmental value, and will not only extend an understanding of the attentional blink but will also facilitate an understanding of the link between environmental concern and pro-environmental behaviors.

\section{Research Objectives and Key Questions}

From the preceding literature review it is readily apparent that environmental advertising is becoming an important academic research topic (Kao \& Du, 2020; Shen et al., 2019). This appears to be in large part because of the intensification in environmental regulations by governments and other bodies, the growing pressures on organizations by stakeholder groups to preserve the environment (Leonidas et al., 2011), the increasing public awareness of ecological issues and the skyrocketing demand for eco-friendly goods (Easterling et al., 1996; Polonsky et al., 1997). 
However, most studies in this field are concerned with bridging environmental advertising and green consumption or production from the perspective of supply chains. Few studies have examined the attentional effectiveness of green advertising across different levels of advertising creativity and across different advertising appeals. Likewise, little prior research has assessed the influence of green dispositions such as environmental concern and environmental value on advertising effectiveness. Accordingly, the present research used an attentional blink task based on the established RVSP paradigm to fill the gap in understanding in relation to these issues, contrasting creative advertisements with standard advertisements and two often-used appeals: warning-based and vision-based appeals. In addition, the study examined the dispositional variables of environmental concern and environmental value to quantify the potential association between green traits and attentional effectiveness with respect to environmental advertisements across different levels of advertising creativity and for distinct appeal types.

The present study represents a first step towards investigating which environmental advertising campaigns might be the most effective for attracting people's environment-related attention in order to persuade environmentally concerned audiences to engage in pro-environmental behaviors. To address these objectives, the current research adopted a RSVP paradigm, within which four kinds of environmental advertisements (warning-based creative advertisements, vision-based creative advertisements, warning-based standard advertisements and vision-based standard advertisements) were appropriately embedded. We believe that this approach has not previously been applied in the field of advertising research.

Given the lack of behavioral measures directly determining attentional effectiveness in advertising, this research adopted an exploratory approach and posed the following four questions:

RQ1: Does an attentional blink occur in environmental advertising?

RQ2: Are creative advertisements or standard advertisements more effective in attracting individuals' attention?

RQ3: Are vision-based appeals or warning-based appeals that are embedded in environmental advertisements more effective in attracting individuals' attention?

RQ4: If an attentional blink occurs in environmental advertising then do environmentally concerned individuals show a greater magnitude of attentional blink as an indicator reflecting the attentional effectiveness of environmental advertising? In other words, is there any association between depositional environmental concern and value and the attentional effectiveness of environmental advertising when measured using the magnitude of the attentional blink?

\section{Methods}

\subsection{Participants}

Using a convenience sampling approach, 52 university students (28 males) aged 18-29 years $(M=23.2, S D=1.83)$ were recruited for monetary compensation. The sample was representative of the population of Chinese college students (i.e., well-educated young adults). All participants were healthy, right-handed and had normal or corrected-to-normal eyesight, without suffering from color blindness/weakness or neurological or psychiatric diseases. Seven participants were excluded because of incomplete data, leaving a final sample of 45 participants. The local ethics committee approved the study.

\subsection{Stimuli and apparatus}

\subsubsection{Pictorial stimuli}

The T1 stimuli comprised 24 warning-based and 24 vision-based pictorial advertisements at 
two different creativity levels (creative vs. standard). The supplementary materials present examples of advertisements that embody warning-based and vision-based appeals. In addition, 96 home landscape pictures were used as neutral distractor items. The T2 stimuli comprised 24 natural landscape pictures across four seasons (six pictures for each season).

All stimuli were transformed via Photoshop software to a standardized picture format (bmp) with dimensions extending $15.38 \mathrm{~cm} \times 9.56 \mathrm{~cm}$ and visual angles of $6.1^{\circ}$ (height) $\times 9.8^{\circ}$ (width). All stimuli achieved the standard of 72 pixels and had no differences in terms of the cluster and luster of color or the contrast and brightness of the entire picture. To highlight the target stimuli in the RSVP stream, the T1 and T2 stimuli were both framed in a red box of 4-point line density.

The T1 advertisements were selected from a larger database of 100 environmental advertisements that had been rated previously by 30 participants on five dimensions: creativity, emotionality, beauty, purity/singularity and environmental association (see Table 1 for further details). All ratings were made using a 5-point Likert scale, where 1 and 5 represented the negative and positive extremes of each dimension. As Table 1 indicates, the 24 warning-based and 24 vision-based pictorial advertisements that were selected for the study were standardised in terms of their average ratings on the five dimensions, with no significant differences, all $p \mathrm{~s}>.05$.

Finally, the images of home landscapes (i.e., the neutral stimuli) and of seasonal landscapes (i.e., the T2 stimuli) had no significant differences in relation to the $\mathrm{T} 1$ advertising stimuli in terms of their size, contrast, colorfulness or brightness.

\section{[INSERT TABLE 1 ABOUT HERE]}

\subsubsection{Environmental concern scale}

The environmental concern scale was devised for Chinese students by Wu and Zhu (2017) based on the "New Environmental Paradigm" and includes 15 items that are rated on a 5-point Likert scale ranging from "entirely disagree" to "entirely agree". In scoring responses, odd-numbered items are positively scored and even-numbered items are reverse scored. For example, participants who choose "entirely disagree" for the seventh item, "Animals and plants enjoy the same right to live as human beings", would be given a score of 1 (or 5 if they choose "entirely agree"); if they then choose "entirely disagree" for the fourth item, "The so-called 'ecological crisis' that humans are facing is an overstatement", then they would be given a score of 5 (or 1 if they choose "entirely agree"). The Cronbach's alpha reliability for this scale is 0.77 .

\subsubsection{Environment-related value scale}

This scale is a three-dimensional measure of environment-related values derived from Stern and Dietz's (1994) findings on the value basis of environmental concern, consisting of egoistic, social-altruistic and biospheric value orientations. The scale was adapted by $\mathrm{Xu}$ (2008) and consists of 11 items with 4, 4, and 3 items, respectively, for the sub-scales of egoistic, social-altruistic and biospheric values. These items are all rated on a 5-point Likert scale, with 1 indicating "very important" and 5 indicating "very unimportant" (with reverse scoring for the egoistic value). In the present study, the Cronbach's alpha reliability for the entire scale was 0.73 .

\subsubsection{Environment-friendly behavior scale}

The environment-friendly behavior scale is a self-administered measure developed by Gong (2008). It is based on the CGSS 2003, which was collected from a valid sample of 5073 Chinese individuals aged 18-69 years through probability proportionate to size (PPS) sampling according to the fifth Nationwide Population Census. The scale includes 10 items that are offered for the participants to rate their own attitudes, building on their specific situation of the year prior to the 
test. Participants are required to rate given behaviors such as "repeatedly use a plastic bag" as "never", "occasionally" or "often", which score 1, 2, and 3 points, respectively. The scale is used widely and its Cronbach's alpha reliability in the present study was 0.84 .

\subsubsection{Emotion-related measures (self-reported depression and anxiety)}

Previous studies have implicated the influence of individuals' anxiety and depression on the magnitude of the attentional blink. To control for this, the present study employed the 20-item Self-rating Depression Scale (SDS; Zung, 1965) and the 20-item Self-rating Anxiety Scale (SAS; Zung, 1971) to measure individuals' emotional characteristics. Both scales are widely used and have excellent culture-appropriateness in terms of reliability, validity, and cultural background. The Cronbach's alpha reliabilities for the SDS and SAS are 0.90 and 0.83 , respectively.

\subsection{Experimental design}

The study manipulated three repeated-measure factors: creativity level of the T1 advertisements (creative vs. standard), appeal type of the T1 advertisements (warning-based vs. vision-based) and probe lag for T2 (lag3 vs. lag8). T1 and T2 accuracies were computed as the average performance collapsed across trials. T2 performance was conditionalized on accurate T1 performance. According to MacLean and Arnell (2010), the magnitude of the attentional blink is the difference between T2 average accuracy at lag8 and lag3, that is, the value of lag8 minus lag3. The order of all the listed scales was counterbalanced across participants and likewise the set of scales was counterbalanced so that they were completed an equal number of times either before or after the attentional blink phase of the study.

\subsection{Experimental procedure}

The experiment was administered using E-prime 2.0 software, with stimuli being presented to participants on a 21-inch display-screen running Windows 7. Each trial began with a $400 \mathrm{~ms}$ fixation cross in the center of the screen to remind participants to initiate the RSVP stream. Participants were required to attend to the screen, particularly the fixation cross. After a $200 \mathrm{~ms}$ blank-screen delay, the RSVP stimulus stream consisting of 2 targets (T1 and T2) and 16 distractors (home landscape pictures) was presented. Each item persisted in view for $83 \mathrm{~ms}$ and was then masked by the next item without any repetition of pictures.

The number of distractors preceding the first target (T1) was determined randomly on each trial and varied between 2 and 5 . That is, the occurrence of $\mathrm{T} 1$ in the stream was varied randomly between positions 3, 4, 5 and 6 to reduce the predictability of the onset of the first target. The second target (T2) appeared either at the third lag (lag3) or eighth lag (lag8) after T1 during the same stream. In other words, T2 was presented following T1 after another 2 or 7 intervening distractors (lag3 vs. lag8, respectively) as depicted in Figure 1. This resulted in a stimulus onset asynchrony (SOA) between the T1 and T2 of $249 \mathrm{~ms}$ for lag 3 and $664 \mathrm{~ms}$ for lag 8. Accordingly, lag3 is within the window of the attentional blink (i.e., within the timeframe of 200-500 ms), whereas lag8 is outside of this window.

\section{[INSERT FIGURE 1 ABOUT HERE]}

Participants were required to answer two questions during each RSVP stimulus stream and to enter their answers using the keyboard. The first question required participants to judge the advertising appeal of the first advertisement (T1), as highlighted in the red border, by selecting "1" (to denote that the advertisement was perceived to be warning-based) or " 2 " (to denote that the advertisement was perceived to be vision-based). The second question asked subjects to judge the season of the second picture highlighted in the red border (T2) from the options of Spring, 
Summer, Autumn and Winter. Only if the response to the T1 question had been correct was the response to the second question included in the subsequent analysis. Finally, to demarcate the end of a RSVP stimulus stream, the fixation cross reappeared to indicate that the next trial was ready to begin. Movement from one trial to the next was self-paced, with no limitations on overall performance time. No feedback on performance was provided during the experiment.

Participants received a practice session prior to the formal experiment that included two blocks of trials with 24 trials in each block. A brief inter-block rest was also introduced. The test order of the two blocks was counterbalanced across participants, with an equal probability of T1 and T2 arising at different time points and reflecting different appeals and levels of creativity. The pictorial stimuli for $\mathrm{T} 1, \mathrm{~T} 2$ and the distractors in the practice session were all randomly selected from a standardized database.

\section{Results}

Participants' T2 performance was analyzed only for those trials in which $\mathrm{T} 1$ had been correctly reported. This is because when T1 trials elicit an incorrect response it is difficult to identify the source of the error (Chun \& Potter, 1995). T2 performance was analysed using a three-factorial, repeated-measures ANOVA, where the factors were creativity level (creative vs. standard advertisements), appeal type (warning-based vs. vision-based) and probe lag (lag3 vs. lag8). Table 2 summarises the findings arising from this ANOVA.

A reliable main effect was observed for creativity level, with creative advertisements at $\mathrm{T} 1$ eliciting significantly greater $\mathrm{T} 2$ accuracy than standard advertisements, $F_{(1,45)}=15.51, M S E=$ $0.03, p<.001, \eta_{\mathrm{p}}{ }^{2}=0.26$. A reliable main effect was also observed for appeal type, with vision-based appeals at $\mathrm{T} 1$ eliciting significantly greater $\mathrm{T} 2$ accuracy than warning-based appeals, $F_{(1,45)}=15.24, M S E=0.04, p<.001, \eta_{\mathrm{p}}{ }^{2}=0.26$. In addition, a reliable main effect of probe lag was evident, with significantly greater T2 accuracy at lag8 than at lag3, $F_{(1,45)}=101.83, M S E=$ $0.08, p<.001, \eta_{\mathrm{p}}{ }^{2}=0.70$, which is indicative of a general attentional blink effect. In other words, attention is continuously changing over time such that switching from one target to another will produce a cost, with the greatest cost arising for the switch between two targets that are close in time (i.e., lag3) than more distant in time (i.e., lag8). Furthermore, a significant interaction was observed between creativity level and probe lag, $F_{(1,44)}=4.81, M S E=0.08, p<.05, \eta_{\mathrm{p}}{ }^{2}=0.10$. All of the remaining interaction effects were not significant, $p s>.05$ (see Table 2).

\section{[INSERT TABLE 2 ABOUT HERE]}

Post-hoc tests were conducted to explore in more detail the creativity level by probe lag interaction (see Figure 2). The analysis indicated that creative advertisements produced significantly higher accuracy than standard advertisements in the lag8 condition, $M D=0.15, t=$ 4.02, Cohen's $d=.60, p<.001$, whereas there was no difference between creative and standard advertisements in the lag3 condition, $M D=0.01, t=0.37$, Cohen's $d=.06, p>.05$. Regardless of the specific type of environmental advertisements (creative or standard), the lag3 condition resulted in poorer accuracy than the lag 8 condition, all $p$ s $<.001$. The creativity level by probe lag interaction is indicative of an increased attentional blink magnitude for creative advertisements relative to standard advertisements.

\section{[INSERT FIGURE 2 ABOUT HERE]}

Pearson correlational analyses were conducted to analyse the potential relationship between environment-related dispositional measures and individual differences in the magnitude of the attentional blink, As Table 3 shows, a significant, positive (partial) correlation (to exclude the 
impact of anxiety and depression) was observed between the magnitude of the attentional blink and altruism value, $r_{(41)}=.33, p<.05$. Furthermore, there were significant (partial) positive correlations between individuals' environmental concern and performance accuracy at both lag3 and lag8. Although no correlation existed between the magnitude of the attentional blink and pro-environmental behavior, reliable associations were found between individuals' pro-environmental behaviors and their environmental concern and environment-related value (except for egoistic value). Taken together, these results suggest that attending to environmental advertising is an important precondition, or at least a facilitator, to provoke pro-environmental behaviors. This facilitation effect is particularly strong when environmental concern as a (mediating factor) can act as a catalyst.

\section{[INSERT TABLE 3 ABOUT HERE]}

\section{Discussion}

In a low-carbon supply chain accompanying the increasing pressures on environmental sustainability and the ecological economy, advertising, as a key approach to marketing, is indispensable to ensure that low-carbon products receive maximum extension (Zhou et al., 2016). Advertising likewise serves a vital role in communicating with consumers in order to echo their concern about the environment and their awareness of eco-friendly initiatives. The present study used a RSVP task to investigate the attentional blink in relation to environmental advertising and gave rise to two important findings. First, the study revealed the existence of a general attentional blink effect for environmental advertisements that involved different appeals and levels of creativity. Second, the study demonstrated a reliable association between the magnitude of the attentional blink effect and individual differences in environment-related dispositions. To our knowledge, this research is the first to examine the attentional blink effect with environmental advertising and the potential association between the magnitude of the attentional blink and individual differences in environment-related dispositions. Below we consider the findings from the study in more detail and discuss their potential implications.

A key result is the evidence garnered for a reliable attentional blink effect in the domain of environmental advertising. Attention is a selective process connecting awareness and action, and it takes charge of allocating people's limited mental capacity to certain stimuli while ignoring other stimuli. In the RSVP paradigm, because two target stimuli appear in close temporal proximity, it is possible to detect the attentional blink effect in terms of reduced accuracy for the second target when there is a shorter lag after presentation of the first target than a longer lag (Raymond et al., 1992). In our study, the attentional blink effect was observed in terms of the reduced accuracy of responding to the second target at lag3 relative to lag8. This observation is consistent with earlier research that has established the attentional blink effect when two target stimuli are embedded in a rapid stream of events and where the second target is presented within the timeframe of 200-500 ms after the first target (Raymond et al., 1992). This attentional blink effect has been established in other domains, including emotion perception (e.g., Keil and Ihssen, 2004) and face perception (e.g., Maratos et al., 2008) as well as when using word-based stimuli (e.g., Olson et al., 2001) or visual images (e.g., Wyble et al., 2013). This present evidence for the existence of an attentional blink effect in the context of environment-related cognition in advertising and marketing domains serves to consolidate the robustness of the effect.

The present study not only provided evidence for a reliable attentional blink effect in relation to environmental advertisements but also demonstrated that the effect is quantitatively modulated 
by advertising creativity, with creative advertisements revealing an increased magnitude of attentional blink compared to standard advertisements. Creativity is a quintessential characteristic of advertisements for advertising practitioners and academics and has widely been considered as the "soul" of advertising (Ang and Low, 2000; El-Murad and West, 2004) and a key determinant of advertising effectiveness. Creative advertisements are considered to involve "difference" (Koslow, 2015) and to be more effective than standard advertisements at attracting viewers' attention (e.g., Sajjacholapunt and Ball, 2014). For example, creative advertisements have been found not only to attract viewers' initial attention but also to increase the amount of attention subsequently directed at them (Sasser and Koslow 2008; Smith et al., 2008). The present research demonstrated a marked interaction between probe lag and the level of advertising creativity, revealing that creative advertisements intensified the magnitude of the attentional blink when compared to standard advertisements. This finding suggests that more attentional priority was attributed to creative than standard advertisements and provides new evidence for the importance of creativity in attaining better attention-related advertising effectiveness.

Another major finding from the present study relates to the observed association between the magnitude of the attentional blink and individual differences in environment-related dispositions that have been implicated in pro-environmental behaviors, such as saving water and electricity, recycling waste and reusing plastic bottles (e.g., Caruana et al., 2014; Kaiser et al., 2007). Our research demonstrates a positive correlation between the magnitude of the attentional blink and an orientation toward environment-related altruism. In addition, the study revealed reliable associations among measures of environmental concern, environmental value and pro-environmental behavior, albeit without a direct association between the magnitude of the attentional blink and pro-environmental behaviors. Consistent with recent findings (Sollberger et al., 2017; Whitman et al., 2018), people who are more environmentally concerned or orientated toward environment-related altruism appear to attend more readily to environment-related information or advertisements during a rapid processing stream (Mostafa, 2007). Indeed, pro-environmental individuals have been found to show higher levels of self-transcendent values (e.g., Nordlund and Garvill, 2002), more prosocial values and behavior (Cameron et al, 1998; Kaiser and Byrka, 2011) and a stronger future orientation (e.g., Ebreo and Vining, 2001). In addition, environmental values and environmental concern have both been observed to be related to certain personality traits such as neuroticism, which, in turn, is linked with enhanced attention to threatening information (e.g., Klein and Harris, 2009; Torkar and Bogner, 2019).

Furthermore, the present study has provided compelling support for the important roles played by advertising creativity and appeal type in relation to individuals' attention to environmental advertisements. Advertising creativity and appeal are two common factors that have been found previously to influence advertising effectiveness. As mentioned above, creativity in advertising is a key issue for advertising practitioners and academic researchers. Considering attention - measured in terms of the attentional blink effect - as a proxy for advertising effectiveness, this study has supported the effect of the creativity of the effectiveness of environmental advertisements, confirming previous findings linking creativity in advertisements to their increased attentional draw (Sasser \& Koslow 2008; Smith et al., 2008) and their enhanced recall (Lehnert et al., 2013; Till and Baack, 2005). As for advertising appeal, two distinct types of appeal were introduced in the present study, that is, warning-based appeals and vision-based appeals. These aimed to attract viewers' attention and achieve effectiveness by presenting either 
negative, environmentally threatening images or positive, environmentally promising images. In both cases these appeals were designed to facilitate people's environmental concern and pro-environmental intent or behavior. Our study demonstrated a significant main effect of advertising appeal, indicating that more attentional resource was engaged in viewing and processing warning-based advertisements than vision-based advertisements. Consistent with our findings, substantial evidence (e.g., Hartmann et al., 2014; Hine and Gifford, 1991) has indicated that exposure to an advertisement featuring a threat appeal related to environmental issues can have a substantial facilitatory impact on environment-related attitude, intention and behavior (e.g., attending to environmental stimuli or engaging in pro-environmental practices). Likewise, Hine and Gifford (1991) reported that exposure to a brief, anti-pollution message produced more verbal commitment (e.g., signing a petition) and financial donations than exposure to a control message. The efficacy of such warning-based advertisements may arise because they are more visually intense, shocking and fear-arousing than vision-based advertisements, which tend to play into more sensory and aesthetic characteristics of emotional processing.

Because the present research is exploratory, there are some limitations that should be considered that may affect the generalizability of the findings. The first is the use of a convenience sample of university students, which comes with the usual caveats, particularly when studying the relationship between environmental attitudes and buying behaviors. Another possible limitation is the use of a laboratory-based experimental approach, which affords advantages in terms of control over variables to facilitate a causal interpretation of findings, but which suffers in terms of ecological validity with respect to real-world advertising contexts (Pieters and Wedel, 2004; Till and Baack, 2005). In this respect, the results should be validated in real-life settings using a large sample with diverse backgrounds. In addition, the associations observed between situation-specific cognition (i.e., attending to environment-related advertisings), individual differences in environment-related dispositions and pro-environmental behaviors, deserves more detailed analysis. In particular, a deeper investigation of the underpinning causal relationship between variables is warranted, with careful consideration being given to the conceptualization of pro-environmental behaviors. Finally, future research should address in more detail the influence of advertising creativity on the attentional blink effect as this seems to be a novel way to investigate attentional processing in advertising, which currently lacks systemic analysis.

\section{Conclusions}

To conclude, we reiterate some important theoretical and applied implications that can be drawn from the present research. First, the study has generalized the attentional blink effect to the domain of creative marketing and, more specifically, to the area of environmental advertising. Second, the study provides the first evidence for an association between the magnitude of the attentional blink and individual differences in environment-related dispositions and value orientations, potentially opening a new avenue for studying the attentional blink. Third, the findings consolidate the importance of advertising creativity by revealing the influence of creativity on the attentional effectiveness of advertisements measured by the RVSP task and resulting differences in the magnitude of the attentional blink effect. Finally, our work implies an advantage from warning-based appeals in environmental advertisements compared to vision-based appeals, with warning-based appeals fostering people's environmental concern and pro-environmental value orientation and potentially even nurturing pro-environmental behaviors. 


\section{References}

Ader, C. R. (1995). A longitudinal study of agenda setting for the issue of environmental pollution. Journalism \& Mass Communication Quarterly, 72(2), 300-311.

Agrawal, N., \& Wan, E. W. (2009). Regulating risk or risking regulation? Construal levels and depletion effects in the processing of health messages. Journal of Consumer Research, 36(3), 448-462.

Albers-Miller, N. D., \& Stafford, M. R. (1999). An international analysis of emotional and rational appeals in services vs goods advertising. Journal of Consumer Marketing, 16(1), 42-57.

Ang, S. H., \& Low, S. Y. (2000). Exploring the dimensions of ad creativity. Psychology \& Marketing, 17(10), 835-854.

Ares, G., Giménez, A., Bruzzone, F., Vidal, L., Antúnez, L., \& Maiche, A. (2013). Consumer visual processing of food labels: Results from an eye-tracking study. Journal of Sensory Studies, 28(2), $138-153$

Arnell, K. M., Stokes, K. A., MacLean, M. H., \& Gicante, C. (2010). Executive control processes of working memory predict attentional blink magnitude over and above storage capacity. Psychological Research, 74, 1-11.

Awagu, C., \& Basil, D. Z. (2016). Fear appeals: The influence of threat orientations. Journal of Social Marketing, 6(4), 361-376.

Baack, D. W., Wilson, R. T., \& Till, B. D. (2008). Creativity and memory effects: Recall, recognition, and an exploration of nontraditional media. Journal of Advertising, 37(4), 85-94.

Bakar, M. H. A., Desa, M. A. M., \& Mustafa, M. (2015). Attributes for image content that attract consumers' attention to advertisements. Procedia-Social \& Behavioral Sciences, 195, 309-314.

Belch, G. E., \& Belch, M. A. (2004). Advertising and promotion: An integrated marketing communications perspective. New York, NY: McGraw-Hill.

Belch, G. E., \& A. Belch, M. (2013). A content analysis study of the use of celebrity endorsers in magazine advertising. International Journal of Advertising, 32(3), 369-389.

Brunson, M. W., \& Reiter, D. K. (1996). Effects of ecological information on judgments about scenic impacts of timber harvest. Journal of Environmental Management, 46(1), 31-41.

Calder, B. J., \& Sternthal, B. (1980). Television commercial wearout: An information processing view. Journal of Marketing Research, 17(2), 173-186.

Cameron, L. D., Brown, P. M., \& Chapman, J. G. (1998). Social value orientations and decisions to take proenvironmental action. Journal of Applied Social Psychology, 28(8), 675-697.

Caruana, R., Glozer, S., Crane, A., \& McCabe, S. (2014). Tourists' accounts of responsible tourism. Annals of Tourism Research, 46, 115-129.

Casado-Aranda, L. A., Martínez-Fiestas, M., \& Sánchez-Fernández, J. (2018). Neural effects of environmental advertising: An fMRI analysis of voice age and temporal framing. Journal of Environmental Management, 206, 664-675.

Champlin, S., Lazard, A., Mackert, M., \& Pasch, K. E. (2014). Perceptions of design quality: An eye tracking study of attention and appeal in health advertisements. Journal of Communication in Healthcare, 7(4), 285-294.

Chang, C. (2006). Seeing the small picture: Ad-self versus ad-culture congruency in international advertising. Journal of Business \& Psychology, 20(3), 445-465.

Chan, K., \& Han, X. (2014). Effectiveness of environmental advertising for hotels. Services Marketing Quarterly, 35(4), 289-303.

Chan, R. Y. (2000). The effectiveness of environmental advertising: the role of claim type and the 
source country green image. International Journal of Advertising, 19(3), 349-375.

Chang, C. T. (2012). Are guilt appeals a panacea in green advertising? The right formula of issue proximity and environmental consciousness. International Journal of Advertising, 31(4), 741-771.

Chekima, B., Wafa, S. A. W. S. K., Igau, O. A., Chekima, S., \& Sondoh Jr, S. L. (2016). Examining green consumerism motivational drivers: Does premium price and demographics matter to green purchasing? Journal of Cleaner Production, 112, 3436-3450.

Chen, M. F. (2016). Impact of fear appeals on pro-environmental behavior and crucial determinants. International Journal of Advertising, 35(1), 74-92

Chen, M. Y., \& Chiu, C. I. (2016). Go green: how to influence the perceived effectiveness of a green product? International Journal of Advertising, 35(4), 622-641.

Chun, M. M., \& Potter, M. C. (1995). A two-stage model for multiple target detection in Rapid Serial Visual Presentation. Journal of Experimental Psychology, 21(1), 109-127.

Coad, A., De Haan, P., \& Woersdorfer, J. S. (2009). Consumer support for environmental policies: An application to purchases of green cars. Ecological Economics, 68(7), 2078-2086.

Colzato, L. S., Spapé, M. M., Pannebakker, M. M., \& Hommel, B. (2007). Working memory and the attentional blink: Blink size is predicted by individual differences in operation span. Psychonomic Bulletin \& Review, 14(6), 1051-1057.

Dahlén, M., Rosengren, S., \& Törn, F. (2008). Advertising creativity matters. Journal of Advertising Research, 48(3), 392-403.

Dale, G., \& Arnell, K. M. (2015). Multiple measures of dispositional global/local bias predict attentional blink magnitude. Psychological Research, 79(4), 534-547.

Dangelico, R. M., \& Vocalelli, D. (2017). "Green Marketing": an analysis of definitions, strategy steps, and tools through a systematic review of the literature. Journal of Cleaner production, 165, 1263-1279.

Daugherty, T., \& Hoffman, E. (2014). eWOM and the importance of capturing consumer attention within social media. Journal of Marketing Communications, 20(1-2), 82-102.

Davis, C., \& Burton, S. (2016). Understanding graphic pictorial warnings in advertising: A replication and extension. Journal of Advertising, 45(1), 33-42.

De Vries, G., Terwel, B. W., Ellemers, N., \& Daamen, D. D. (2015). Sustainability or profitability? How communicated motives for environmental policy affect public perceptions of corporate greenwashing. Corporate Social Responsibility \& Environmental Management, 22(3), 142-154.

Dickinson, S., \& Holmes, M. (2008). Understanding the emotional and coping responses of adolescent individuals exposed to threat appeals. International Journal of Advertising, 27(2), 251-278.

Do Paço, A. M. F., \& Raposo, M. L. B. (2008). Determining the characteristics to profile the "green" consumer: An exploratory approach. International Review on Public \& Nonprofit Marketing, 5(2), 129-140.

Easterling, D., Kenworthy, A., \& Nemzoff, R. (1996). The greening of advertising: A twenty-five year look at environmental advertising. Journal of Marketing Theory \& Practice, 4(1), 20-34.

Ebreo, A., \& Vining, J. (2001). How similar are recycling and waste reduction? Future orientation and reasons for reducing waste as predictors of self-reported behavior. Environment \& Behavior, 33(3), 424-448.

El-Murad, J., \& West, D. C. (2004). The definition and measurement of creativity: What do we know? Journal of Advertising Research, 44(2), 188-201.

Fillis, I. (2002). An Andalusian dog or a rising star? Creativity and the marketing/entrepreneurship 
interface. Journal of Marketing Management, 18(3-4), 379-395.

Foster, C., \& Green, K. (2000). Greening the innovation process. Business Strategy and the Environment, 9(5), 287-303.

Fransson, N., \& Gärling, T. (1999). Environmental concern: Conceptual definitions, measurement methods, and research findings. Journal of Environmental Psychology, 19(4), 369-382.

Gong, W. (2008). A gender-based comparison of Chinese urban residents' environmentally friendly behaviors. Journal of China University of Geosciences, 8(6), 37-42.

Goodrich, K. (2011). Anarchy of effects? Exploring attention to online advertising and multiple outcomes. Psychology \& Marketing, 28(4), 417-440.

Greenberg, A. S. (2012). The role of visual attention in internet advertising: Eleven questions and a score of answers. Journal of Advertising Research, 52(4), 400-404.

Grigaliunaite, V., \& Pileliene, L. (2016). Emotional or rational? The determination of the influence of advertising appeal on advertising effectiveness. Scientific Annals of Economics \& Business, 63(3), 391-414.

Griskevicius, V., Tybur, J. M., \& Van den Bergh, B. (2010). Going green to be seen: Status, reputation, and conspicuous conservation. Journal of Personality \& Social Psychology, 98(3), 392-404.

Hartmann, P., \& Apaolaza-Ibanez, V. (2010). Beyond savanna: An evolutionary and environmental psychology approach to behavioral effects of nature scenery in green advertising. Journal of Environmental Psychology, 30(1), 119-128.

Hartmann, P., Apaolaza, V., \& Alija, P. (2013). Nature imagery in advertising: Attention restoration and memory effects. International Journal of Advertising, 32(2), 183-210.

Hartmann, P., Apaolaza, V., D’souza, C., Barrutia, J. M., \& Echebarria, C. (2014). Environmental threat appeals in green advertising: The role of fear arousal and coping efficacy. International Journal of Advertising, 33(4), 741-765.

Hartmann, P., Apaolaza, V., \& Eisend, M. (2016). Nature imagery in non-green advertising: The effects of emotion, autobiographical memory, and consumer's green traits. Journal of Advertising, 45(4), 427-440.

Heath, R., Brandt, D., \& Nairn, A. (2006). Brand relationships: Strengthened by emotion, weakened by attention. Journal of Advertising Research, 46(4), 410-419.

Hine, D. W., \& Gifford, R. (1991). Fear appeals, individual differences, and environmental concern. Journal of Environmental Education, 23(1), 36-41.

Hornik, J., Ofir, C., \& Rachamim, M. (2017). Advertising appeals, moderators, and impact on persuasion: A quantitative assessment creates a hierarchy of appeals. Journal of Advertising Research, 57(3), 305-318.

Hsieh, Y. C., \& Chen, K. H. (2011). How different information types affect viewer's attention on internet advertising. Computers in Human Behavior, 27(2), 935-945

Huang, H. (2016). Media use, environmental beliefs, self-efficacy, and pro-environmental behavior. Journal of Business Research, 69(6), 2206-2212.

Jäger, A. K., \& Weber, A. (2020). Can you believe it? The effects of benefit type versus construal level on advertisement credibility and purchase intention for organic food. Journal of Cleaner Production, 257, 120543.

Janiszewski, C. (1998). The influence of display characteristics on visual exploratory search behavior. Journal of Consumer Research, 25(3), 290-301.

Jenkins, H., \& Yakovleva, N. (2006). Corporate social responsibility in the mining industry: 
Exploring trends in social and environmental disclosure. Journal of Cleaner Production, 14(3-4), 271-284.

Jovanović, P., Vlastelica, T., \& Kostić, S. C. (2017). Impact of advertising appeals on purchase intention. Management: Journal of Sustainable Business \& Management Solutions in Emerging Economies, 21(81), 35-45.

Kaiser, F. G., \& Byrka, K. (2011). Environmentalism as a trait: Gauging people's prosocial personality in terms of environmental engagement. International Journal of Psychology, 46(1), 71-79.

Kaiser, F. G., Oerke, B., \& Bogner, F. X. (2007). Behavior-based environmental attitude: Development of an instrument for adolescents. Journal of Environmental Psychology, 27(3), 242-251.

Kaltenborn, B. P., \& Bjerke, T. (2002). Associations between environmental value orientations and landscape preferences. Landscape \& Urban Planning, 59(1), 1-11.

Kanchanapibul, M., Lacka, E., Wang, X., \& Chan, H. K. (2014). An empirical investigation of green purchase behaviour among the young generation. Journal of Cleaner Production, 66, 528-536.

Kan, Y., Duan, H., Chen, X., Wang, X., Xue, W., \& Hu, W. (2019). Attentional blink affected by acute stress in women: The role of affective stimuli and attentional resources. Consciousness \& Cognition, 75, 102796.

Kao, T. F., \& Du, Y. Z. (2020). A study on the influence of green advertising design and environmental emotion on advertising effect. Journal of Cleaner Production, 242, 118294.

Kees, J., Burton, S., Andrews, J. C., \& Kozup, J. (2010). Understanding how graphic pictorial warnings work on cigarette packaging. Journal of Public Policy \& Marketing, 29(2), 265-276.

Keil, A., \& Ihssen, N. (2004). Identification facilitation for emotionally arousing verbs during the attentional blink. Emotion, 4(1), 23-35.

Ketelsen, M., Janssen, M., \& Hamm, U. (2020). Consumers' response to environmentally-friendly food packaging: A systematic review. Journal of Cleaner Production, 120123.

Kim, Y., \& Choi, S. M. (2005). Antecedents of green purchase behavior: An examination of collectivism, environmental concern, and PCE. Advances in Consumer Research, 32, 592-599.

Klein, W. M., \& Harris, P. R. (2009). Self-affirmation enhances attentional bias toward threatening components of a persuasive message. Psychological Science, 20(12), 1463-1467.

Kong, S., Huang, Z., Scott, N., Zhang, Z. A., \& Shen, Z. (2019). Web advertisement effectiveness evaluation: Attention and memory. Journal of Vacation Marketing, 25(1), 130-146.

Koslow, S. (2015). I love creative advertising: What it is, when to call for it, and how to achieve it. Journal of Advertising Research, 55(1), 5-8.

Kronrod, A., Grinstein, A., \& Wathieu, L. (2012). Go green! Should environmental messages be so assertive?. Journal of Marketing, 76(1), 95-102.

Kurisu, K., Kimura, N., \& Hanaki, K. (2019). Expression effects of public service advertisements on intentions to act for global warming. Journal of Cleaner Production, 218, 1045-1054.

Lehnert, K., Till, B. D., \& Carlson, B. D. (2013). Advertising creativity and repetition: Recall, wearout and wearin effects. International Journal of Advertising, 32(2), 211-231.

Leonidou, L. C., Leonidou, C. N., Palihawadana, D., \& Hultman, M. (2011). Evaluating the green advertising practices of international firms: A trend analysis. International Marketing Review, 28(1), 6-33.

Li, Q., Sun, H., Zhang, H., Li, W., \& Ouyang, M. (2020). Design investment and advertising decisions in direct-sales closed-loop supply chains. Journal of Cleaner Production, 250, 119552.

Lou, Y., Meng, X., Yang, J., Zhang, S., Long, Q., \& Yuan, J. (2016). The impact of extraversion on 
attentional bias to pleasant stimuli: neuroticism matters. Experimental Brain Research, 234(3), 721-731.

Low, G. S., \& Mohr, J. J. (2000). Advertising vs sales promotion: A brand management perspective. Journal of Product \& Brand Management, 9(6), 389-414.

MacLean, M. H., \& Arnell, K. M. (2010). Personality predicts temporal attention costs in the attentional blink paradigm. Psychonomic Bulletin \& Review, 17(4), 556-562.

MacLean, M. H., Arnell, K. M., \& Busseri, M. A. (2010). Dispositional affect predicts temporal attention costs in the attentional blink paradigm. Cognition \& Emotion, 24(8), 1431-1438.

Maratos, F. A., Mogg, K., \& Bradley, B. P. (2008). Identification of angry faces in the attentional blink. Cognition \& Emotion, 22(7), 1340-1352.

Marchand, J., \& Filiatrault, P. (2002). AIDS prevention advertising: Different message strategies for different communication objectives. International Journal of Nonprofit \& Voluntary Sector Marketing, 7(3), 271-287.

Matthes, J. (2019). Uncharted territory in research on environmental advertising: Toward an organizing framework. Journal of Advertising, 48(1), 91-101.

McKenzie-Mohr, D. (2000). Fostering sustainable behavior through community-based social marketing. American Psychologist, 55(5), 531-537.

Mobley, C., \& Kilbourne, W. (2013). Gender differences in pro-environmental intentions: A cross-national perspective on the influence of self-enhancement values and views on technology. Sociological Inquiry, 83(2), 310-332.

Morgan, N. A., Anderson, E. W., \& Mittal, V. (2005). Understanding firms' customer satisfaction information usage. Journal of Marketing, 69(3), 131-151.

Moriarty, S. E. (1991). Creative advertising: Theory and practice. Upper Saddle River, NJ: Prentice Hall.

Mostafa, M. M. (2007). Gender differences in Egyptian consumers' green purchase behaviour: the effects of environmental knowledge, concern and attitude. International Journal of Consumer Studies, 31(3), 220-229.

Noble, G., Pomering, A., \& Johnson, L. W. (2014). Gender and message appeal: Their influence in a pro-environmental social advertising context. Journal of Social Marketing, 4(1), 4-21.

Nordlund, A. M., \& Garvill, J. (2002). Value structures behind proenvironmental behavior. Environment \& Behavior, 34(6), 740-756.

Olson, I. R., Chun, M. M., \& Anderson, A. K. (2001). Effects of phonological length on the attentional blink for words. Journal of Experimental Psychology, 27(5), 1116-1123.

Parguel, B., Benoît-Moreau, F., \& Russell, C. A. (2015). Can evoking nature in advertising mislead consumers? The power of 'executional greenwashing'. International Journal of Advertising, 34(1), 107-134.

Phillips, B. J., \& McQuarrie, E. F. (2004). Beyond visual metaphor: A new typology of visual rhetoric in advertising. Marketing theory, 4(1-2), 113-136.

Pieters, R., Warlop, L., \& Wedel, M. (2002). Breaking through the clutter: Benefits of advertisement originality and familiarity for brand attention and memory. Management Science, 48(6), 765-781.

Pieters, R., \& Wedel, M. (2004). Attention capture and transfer in advertising: Brand, pictorial, and text-size effects. Journal of Marketing, 68(2), 36-50.

Pilelienè, L., \& Grigaliūnaite, V. (2016). Influence of print advertising layout complexity on visual attention. Eurasian Business Review, 6(2), 237-251. 
Polonsky, M. J., Carlson, L. C., Grove, S., \& Kangun, N. (1997). International environmental marketing claims: Real changes or simple posturing? International Marketing Review, 14(4), 218-232.

Rademaker, C. A., Royne, M. B., \& Wahlund, R. (2015). Eco-harmful media perceptions and consumer response to advertising. Journal of Cleaner Production, 108, 799-807.

Raymond, J. E., Shapiro, K. L., \& Arnell, K. M. (1992). Temporary suppression of visual processing in an RSVP Task: An attentional blink? Journal of Experimental Psychology, 18(3), 849-860.

Rios, F. J. M., Moreno, F. F., \& Soriano, P. C. A. (2006). Improving attitudes toward brands with environmental associations: An experimental approach. Journal of Consumer Marketing, 23(1), 26-33.

Roberts, T. R. (1996). Assessing the environmental fate of agrochemicals. Journal of Environmental Science \& Health Part B, 31(3), 325-335.

Rosbergen, E., Pieters, R., \& Wedel, M. (1997). Visual attention to advertising: A segment-level analysis. Journal of Consumer Research, 24(3), 305-314.

Rossiter, J. R., \& Bellman, S. (2005). Marketing communications. Upper Saddle River, NJ: Pearson/Prentice Hall.

Sajjacholapunt, P., \& Ball, L. J. (2014). The influence of banner advertisements on attention and memory: Human faces with averted gaze can enhance advertising effectiveness. Frontiers in Psychology, 5, 166.

Sasser, S. L., \& Koslow, S. (2008). Desperately seeking advertising creativity: Engaging an imaginative "3Ps" research agenda. Journal of Advertising, 37(4), 5-20.

Schlegelmilch, B. B., Bohlen, G. M., \& Diamantopoulos, A. (1996). The link between green purchasing decisions and measures of environmental consciousness. European Journal of Marketing, 30(5), 35-56.

Schmuck, D., Matthes, J., Naderer, B., \& Beaufort, M. (2018). The effects of environmental brand attributes and nature imagery in green advertising. Environmental Communication, 12(3), 414-429.

Sharma, S. \& Singh, R. (2006), Advertising: Planning and implementation. New Delhi: PHI Learning Pvt. Ltd.

Shen, B., Liu, S., Zhang, T., \& Choi, T. M. (2019). Optimal advertising and pricing for new green products in the circular economy. Journal of Cleaner Production, 233, 314-327.

Shen, W. B., Wang, M. J., Yuan, Y., Bai, H. P., \& Hua, M. F. (in press-a). Beauty is not in the eye but in the inner head: Evidence from environmental advertising. Psychology of Aesthetics, Creativity \& the Arts.

Shen, W. B., Liu, Z. Y., Ball, L. J., Huang, T. Z., Yuan, Y., Bai, H. P., \& Hua, M. F. (in press-b). Easy to remember, easy to forget? The memorability of creative advertisements. Creativity Research Journal.

Shukor, M. S., Sulaiman, Z., Thoo, A. C., \& Zakuan, N. (2015). The effect of emotional versus rational appeal in advertising on Malaysian consumers' purchase intention of hybrid car. Applied Mechanics \& Materials, 11(24), 14106-14111.

Simola, J., Kuisma, J., Oörni, A., Uusitalo, L., \& Hyönä, J. (2011). The impact of salient advertisements on reading and attention on web pages. Journal of Experimental Psychology. Applied, 17(2), 174-190.

Smith, R. E., Chen, J., \& Yang, X. (2008). The impact of advertising creativity on the hierarchy of effects. Journal of Advertising, 37(4), 47-62.

Smith, R. E., MacKenzie, S. B., Yang, X., Buchholz, L. M., \& Darley, W. K. (2007). Modeling the determinants and effects of creativity in advertising. Marketing Science, 26(6), 819-833. 
Smith, R. E., \& Yang, X. (2004). Toward a general theory of creativity in advertising: Examining the role of divergence. Marketing Theory, 4(1-2), 31-58.

Sollberger, S., Bernauer, T., \& Ehlert, U. (2017). Predictors of visual attention to climate change images: An eye-tracking study. Journal of Environmental Psychology, 51, 46-56.

Šomplák, R., Kůdela, J., Smejkalová, V., Nevrlý, V., Pavlas, M., \& Hrabec, D. (2019). Pricing and advertising strategies in conceptual waste management planning. Journal of Cleaner Production, 239 , 118068.

Stern, P. C., \& Dietz, T. (1994). The value basis of environmental concern. Journal of Social Issues, 50(3), 65-84.

Stone, G., Besser, D., \& Lewis, L. E. (2000). Recall, liking, and creativity in TV commercials: A new approach. Journal of Advertising Research, 40(3), 7-18.

Tang, M. F., Ford, L., Arabzadeh, E., Enns, J. T., Visser, T. A., \& Mattingley, J. B. (2020). Neural dynamics of the attentional blink revealed by encoding orientation selectivity during rapid visual presentation. Nature Communications, 11(1), 1-14.

Till, B. D., \& Baack, D. W. (2005). Recall and persuasion: Does creative advertising matter? Journal of Advertising, 34(3), 47-57.

Torkar, G., \& Bogner, F. X. (2019). Environmental values and environmental concern. Environmental Education Research, 25(10), 1570-1581.

Torres, I. M., Sierra, J. J., \& Heiser, R. S. (2007). The effects of warning-label placement in print ads: A social contract perspective. Journal of Advertising, 36(2), 49-62.

Tseng, S. C., \& Hung, S. W. (2013). A framework identifying the gaps between customers' expectations and their perceptions in green products. Journal of Cleaner Production, 59, 174-184.

Trutti, A. C., Sjoerds, Z., \& Hommel, B. (2019). Attentional blink and putative noninvasive dopamine markers: Two experiments to consolidate possible associations. Cognitive, Affective, \& Behavioral Neuroscience, 19(6), 1444-1457.

VanDyke, M. S., \& Tedesco, J. C. (2016). Understanding green content strategies: An analysis of environmental advertising frames from 1990 to 2010. International Journal of Strategic Communication, 10(1), 36-50.

Van Vugt, M. K., \& Slagter, H. A. (2014). Control over experience? Magnitude of the attentional blink depends on meditative state. Consciousness \& Cognition, 23, 32-39.

Verbeke, W., \& Ward, R. W. (2006). Consumer interest in information cues denoting quality, traceability and origin: An application of ordered probit models to beef labels. Food Quality and Preference, 17(6), 453-467.

Vogel, T., \& Villegas, J. (2011). Exploring creativity in advertising agencies: A holistic approach. In American Academy of Advertising Proceedings (Online) (p. 99). American Academy of Advertising.

Walker, K., \& Wan, F. (2012). The harm of symbolic actions and green-washing: Corporate actions and communications on environmental performance and their financial implications. Journal of Business Ehics, 109(2), 227-242.

Wang, T. C., Tsai, C. L., \& Tang, T. W. (2018). Exploring advertising effectiveness of tourist hotels' marketing images containing nature and performing arts: An eye-tracking analysis. Sustainability, 10(9), 3038.

Wedel, M., Pieters, R., \& Liechty, J. (2008). Attention switching during scene perception: How goals influence the time course of attention across advertisements. Journal of Experimental Psychology: Applied, 14(2), 129-138. 
Whitman, J. C., Zhao, J., Roberts, K. H., \& Todd, R. M. (2018). Political orientation and climate concern shape visual attention to climate change. Climatic Change, 147(3-4), 383-394.

Willems, C., \& Martens, S. (2016). Time to see the bigger picture: Individual differences in the attentional blink. Psychonomic Bulletin \& Review, 23(5), 1289-1299.

Willemsen, M. C. (2005). The new EU cigarette health warnings benefit smokers who want to quit the habit: Results from the Dutch continuous survey of smoking habits. European Journal of Public Health, 15(4), 389-392.

Wilson, R. T., Baack, D. W., \& Till, B. D. (2015). Creativity, attention and the memory for brands: an outdoor advertising field study. International Journal of Advertising, 34(2), 232-261.

Wilson, R. T., \& Casper, J. (2016). The role of location and visual saliency in capturing attention to outdoor advertising: How location attributes increase the likelihood for a driver to notice a billboard ad. Journal of Advertising Research, 56(3), 259-273.

World Health Organization (2008). Protecting Health from Climate Change: A Toolkit for Event Organisers. Available online at: http://www.who.int/worldhealth-day/toolkit/toolkit_en.pdf

Wu, L. \& Zhu, Y. (2017). Revision of New Ecological Paradigm (NEP) scale in urban students in China and its reliability and validity test. Journal of Nanjing University of Technology, 16(2), 53-61.

Wyble, B., Folk, C., \& Potter, M. (2013). Contingent attentional capture by conceptually relevant images. Journal of Experimental Psychology: Human Perception \& Performance, 39(3), 861-871.

$\mathrm{Xu}, \mathrm{M}$. (2008). The cognition of environmental sustainability between value orientation and the attitude toward energy consumption. Retrieved from National Cheng Kung University.

Yang, X., \& Smith, R. E. (2009). Beyond attention effects: Modeling the persuasive and emotional effects of advertising creativity. Marketing Science, 28(5), 935-949.

Yoo, C. Y., Kim, K., \& Stout, P. A. (2004). Assessing the effects of animation in online banner advertising: Hierarchy of effects model. Journal of Interactive Advertising, 4(2), 49-60.

Zhang, X., \& Yuan, S. M. (2018). An eye tracking analysis for video advertising: Relationship between advertisement elements and effectiveness. IEEE Access, 6, 10699-10707.

Zhang, H., Sun, J., Liu, F., \& Knight, J. G. (2014). Be rational or be emotional: Advertising appeals, service types and consumer responses. European Journal of Marketing, 48(11/12), 2105-2126.

Zhou, Y., Bao, M., Chen, X., \& Xu, X. (2016). Co-op advertising and emission reduction cost sharing contracts and coordination in low-carbon supply chain based on fairness concerns. Journal of Cleaner Production, 133, 402-413.

Zinkhan, G. M., \& Carlson, L. (1995). Green advertising and the reluctant consumer. Journal of Advertising, 24(2), 1-6.

Zung, W. W. (1965). A self-rating depression scale. Archives of General Psychiatry, 12(1), 63-70.

Zung, W. W. (1971). A rating instrument for anxiety disorders. Psychosomatics, 12(6), 371-379. 
Table 1 Mean ratings (with standard deviations) for creativity, emotionality, beauty, purity/singularity and association with the environment for different types of environmental advertising that manipulated advertising creativity (creative vs. standard) and appeal type (warning-based vs. vision-based)

\begin{tabular}{lllllll}
\hline \multicolumn{2}{c}{ Advertising Type } & Creativity & Emotionality & Beauty & Purity/singularity & Association \\
\hline \multirow{2}{*}{ Warning-based } & Creative & $3.87(0.09)$ & $3.78(0.12)$ & $3.66(0.21)$ & $3.69(0.14)$ & $3.74(0.18)$ \\
& Standard & $3.41(0.10)$ & $3.76(0.11)$ & $3.64(0.10)$ & $3.70(0.12)$ & $3.73(0.10)$ \\
\multirow{2}{*}{ Vision-based } & Creative & $3.66(0.16)$ & $3.49(0.19)$ & $3.68(0.18)$ & $3.64(0.17)$ & $3.63(0.14)$ \\
& Standard & $3.13(0.07)$ & $3.46(0.14)$ & $3.60(0.14)$ & $3.59(0.11)$ & $3.52(0.12)$ \\
\hline
\end{tabular}

Note: Creativity refers to the perceived creativity of an advertisement, emotionality refers to the perceived emotionality of an advertisement, beauty refers to the perceived beauty of an advertisement, purity refers to the perceived singularity/pureness of an advertisements in terms of its content or its focus on only a single dimension or theme and association refers to the perceived thematic association of an advertisement with the environment. 
Table 2 Summary of ANOVA results showing significant main effects and interaction effects

\begin{tabular}{llllll}
\hline Effect & Sum of Squares & Mean Square & $\mathrm{F}$ & $\mathrm{p}$ & $\eta^{2} \mathrm{p}$ \\
\hline lag & 8.464 & 8.464 & 101.832 & $<.001$ & 0.698 \\
appeal & 0.472 & 0.472 & 15.243 & $<.001$ & 0.257 \\
creativity & 0.582 & 0.582 & 15.506 & $<.001$ & 0.261 \\
lag x appeal & $9.000 \mathrm{e}-5$ & $9.000 \mathrm{e}-5$ & 0.003 & 0.955 & 0.000 \\
lag x creativity & 0.401 & 0.401 & 4.814 & 0.034 & 0.099 \\
appeal x creativity & 0.032 & 0.032 & 0.858 & 0.359 & 0.019 \\
lag x appeal x creativity & 0.009 & 0.009 & 0.195 & 0.661 & 0.004 \\
\hline
\end{tabular}


Table 3 Partial correlations between the magnitude of the attentional blink (lag8 minus lag3) and environment-related measures

\begin{tabular}{llllllll}
\hline variables & (2) & (3) & (4) & (5) & 6 & ( ) & pro-environmental behavior \\
\hline (1) lag3 & $0.45^{* * *}$ & -0.25 & $0.31^{*}$ & 0.21 & -0.04 & 0.26 & 0.14 \\
(2) lag8 & & $0.74^{* * * *}$ & $0.43^{* * *}$ & $0.32^{*}$ & 0.27 & 0.21 & 0.19 \\
(3) (lag8-lag3) & & & 0.24 & 0.18 & $0.33^{*}$ & 0.04 & 0.10 \\
(4) environmental concern & & & & 0.09 & $0.40^{* *}$ & $0.45^{* *}$ & $0.39^{*}$ \\
(5) egoistic & & & & & 0.26 & $0.34^{*}$ & 0.04 \\
(6) altruistic & & & & & & $0.51^{* * *}$ & $0.32^{*}$ \\
(7) biospheric & & & & & & & $0.49^{* * *}$ \\
\hline
\end{tabular}

Note: $* p<.05, * * p<.01, * * * p<.001$. 


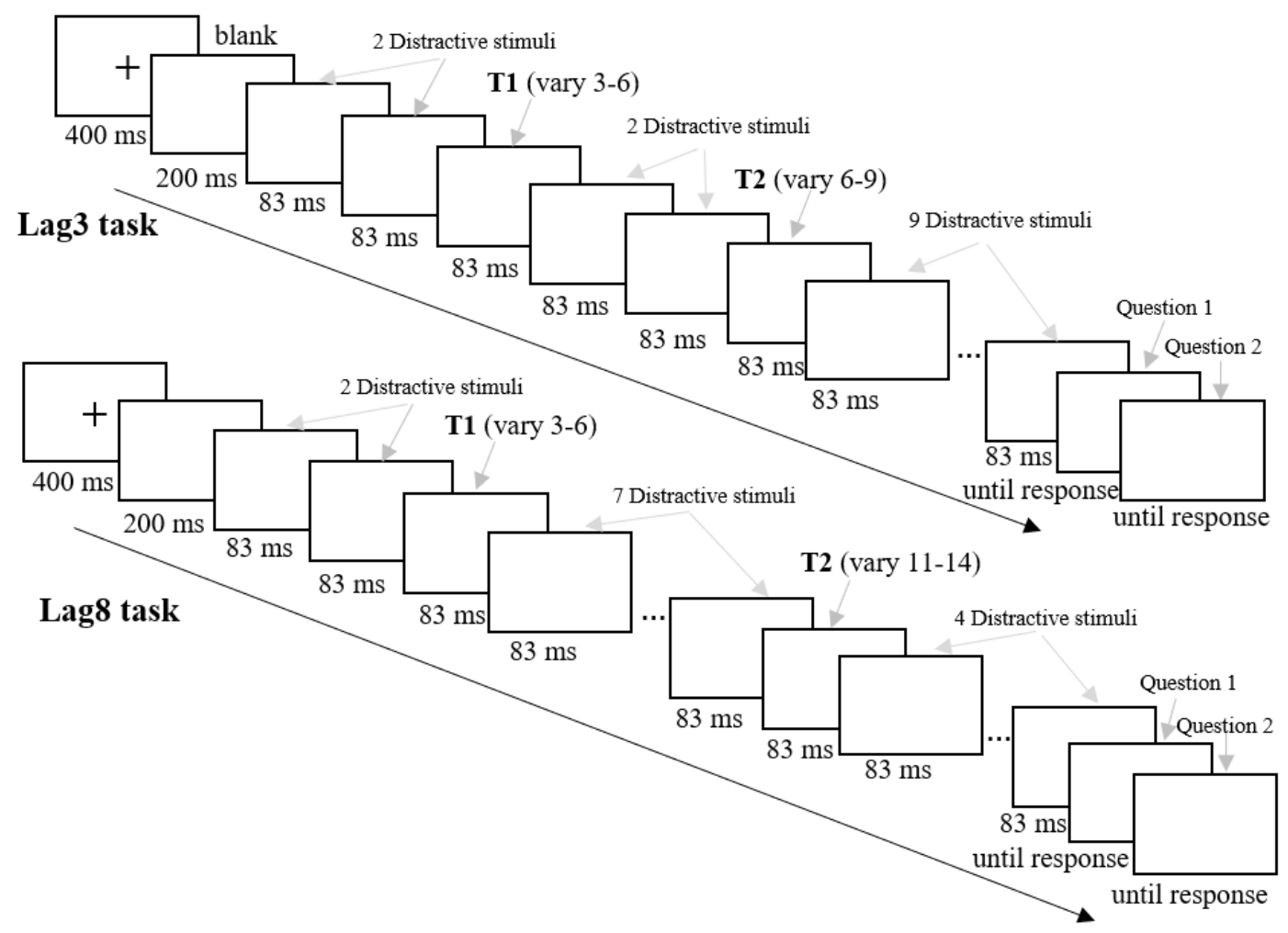

Figure 1 A schematic illustration of one trial from the lag 3 condition and one trial from the lag8 condition 


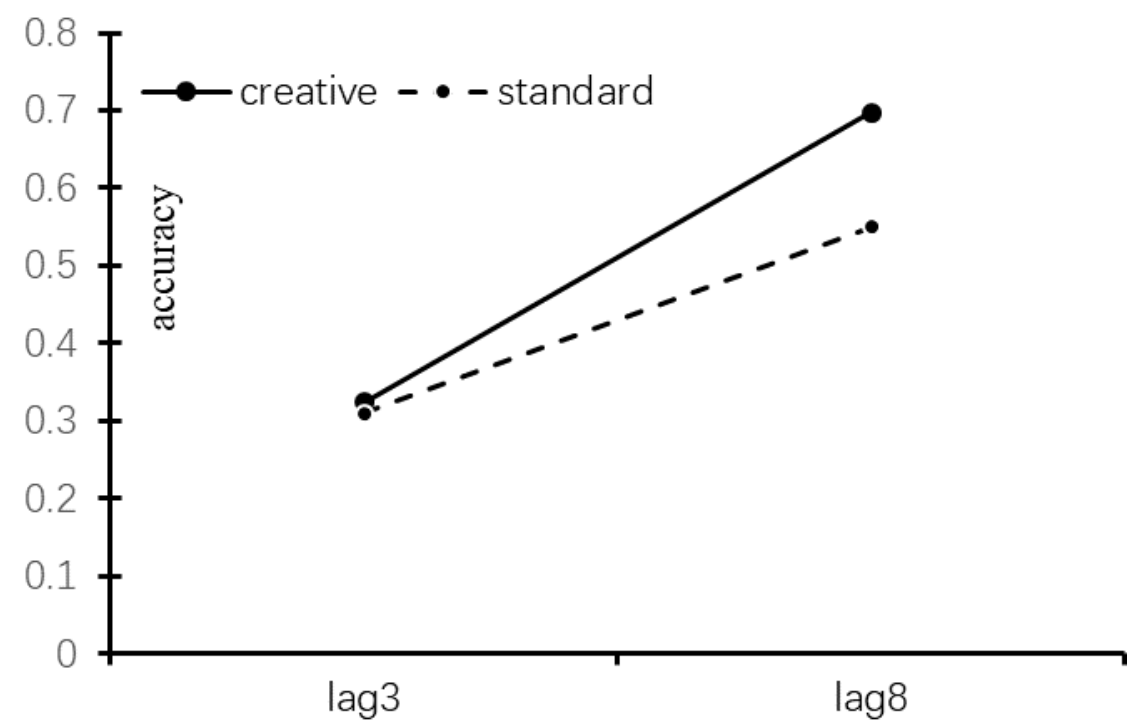

Figure 2 The interaction of probe lag (lag3 vs. lag8) and advertisement type (creative vs. standard) in relation to the accuracy (proportion correct) of responses to T2 


\section{Supplementary Materials}

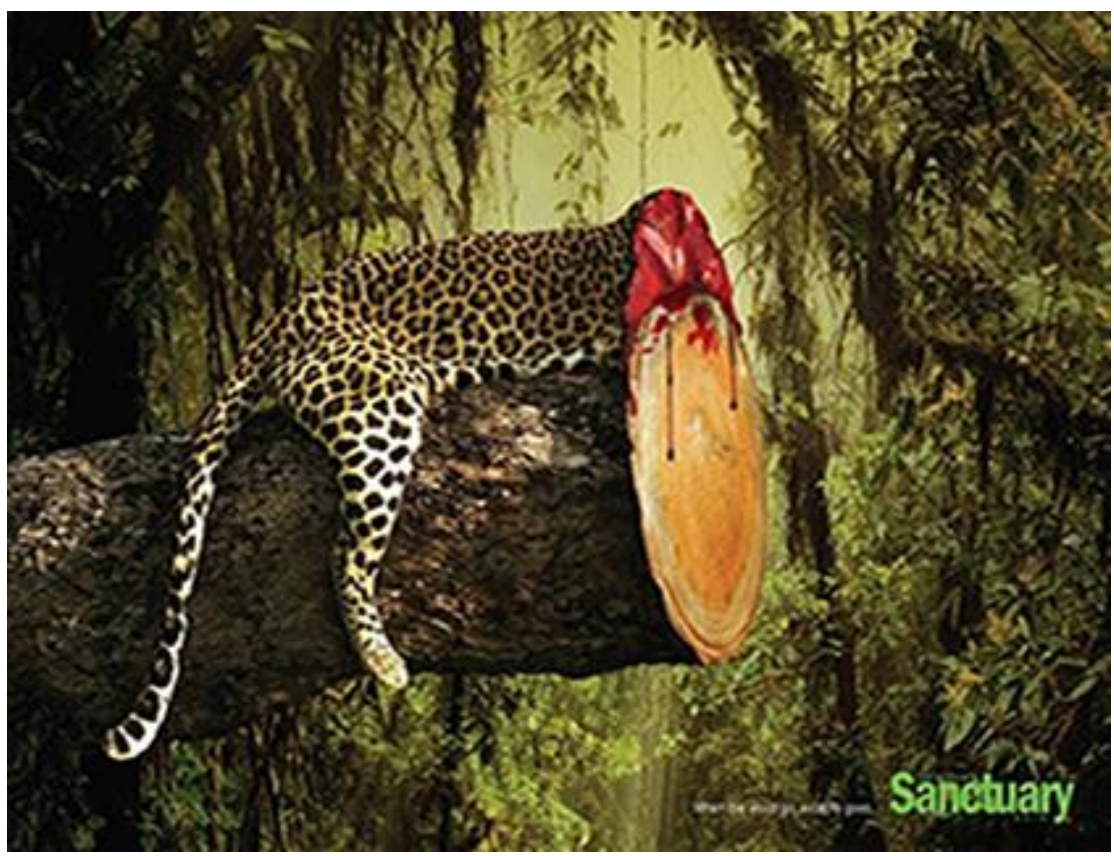

An example of a warning-based environmental advertisement

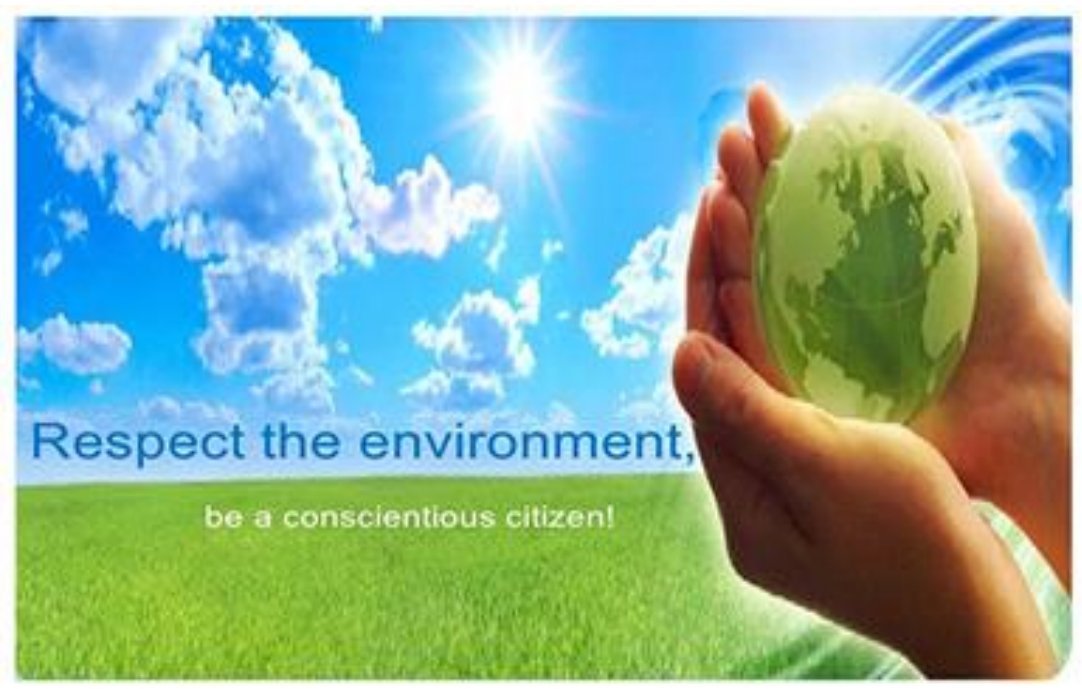

An example of a vision-based environmental advertisement 